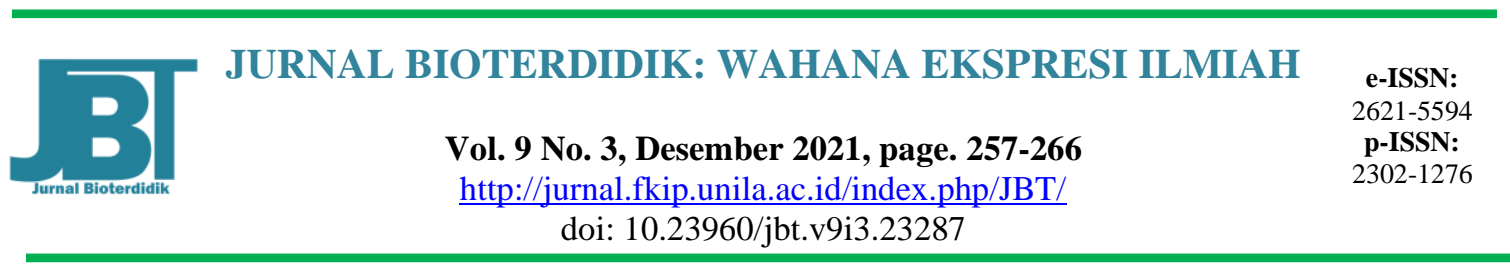

\title{
Keanekaragaman Pari Hasil Tangkapan Nelayan di TPI Karangantu Banten
}

\author{
Erreull Isyhadu*, Dinda Rizqi, Fenia Alya, Tia Azizah \\ *Pendidikan Biologi, Fakultas Keguruan dan Ilmu Pendidikan, Universitas Sultan Ageng Tirtayasa, Jl. \\ Ciwaru Raya No. 25, Cipare, Kec. Serang, Kota. Serang, Indonesia \\ *e-mail:2224190036@untirta.ac.id
}

Abstract: Stingray Diversity the Catch of Fishermen at TPI Karangantu Banten. This study aims to determine the diversity of rays caught by fishermen in TPI Karangantu Banten. This research uses interview method and literature review. The discussion of the observations includes classification, habitat, characteristics, and conservation status. The results of this study indicate that there is a diversity of rays, namely the results of the families obtained from the observations are Rhinopteridae, Dasyatidae, and Gymnuridae). From the results of the calculation of the species diversity index using the Shannon Wiener formula, it is included in the medium category. This diversity can be used as knowledge and inventory for biodiversity, especially the chondrichthyes class in TPI Karangantu, Serang, Banten.

Keywords: Chondrichthyes, Karangantu fish auction, stingray, species diversity,

\begin{abstract}
Abstrak: Keanekaragaman Pari Hasil Tangkapan Nelayan di TPI Karangantu Banten. Penelitian ini bertujuan untuk mengetahui keanekaragaman pari hasil tangkapan nelayan di TPI Karangantu Banten. Penelitian ini menggunakan metode wawancara dan kajian pustaka. Pembahasan hasil pengamatan meliputi klasifikasi, habitat, karakteristik, dan status konservasi. Hasil penelitian ini menunjukan bahwa terdapat keragaman pari yakni dari hasil famili yang diperoleh dari hasil pengamatan adalah Rhinopteridae, Dasyatidae, dan Gymnuridae). Dari hasil perhitungan indeks keanekaragaman spesies dengan rumus Shannon wiener termsuk kedalam kategori sedang. Sejumlah keanekaragaman tersebut dapat menjadi pengetahuan dan inventarisasi untuk biodiversitas khususnya kelas chondrichthyes di TPI Karangantu, Serang, Banten.
\end{abstract}

Kata kunci: Chondrichthyes, ikan pari, keragaman spesies, tempat pelelangan ikan Karangantu 


\section{PENDAHULUAN}

Indonesia adalah salah satu negara yang memanfaatkan sumber daya alam hasil tangkapan lautnya, salah satunya yaitu ikan pari. Ikan pari termasuk kedalam kelas Chondrichthyes. Chondrichthyes merupakan invertebrate rendah yang memiliki columna vertebralis sempurna yang terpisah satu sama lain sehingga mudah membengkokkan tubuhnya. Chondrichthyes memiliki karakteristik adanya tulang rawan dan tidak mempunyai sisik, termasuk kelas primitif umur 450 juta tahun yang lalu dan sekarang tinggal 300 spesies. Misalnya ikan pari, ikan hiu dan chimaeras (Burhanuddin, A. 2014).

Kelas Chondrichthyes terbagi menjadi 2 subkelas, yaitu Subkelas Elasmobranchii dan Subkelas Holocephali. Subkelas Elasmobranchii terbagi menjadi tiga ordo, yaitu Squaliformes, Rajiformes dan Lamniformes. Sedangkan subkelas Holocephali memiliki 2 famili yang umum dikenal, yaitu Chimaeridae dan Rhinochimaeridae (Burhanuddin, A. 2014).

Kelas Chondrichthyes terbagi menjadi 2 subkelas, yaitu Subkelas Elasmobranchii dan Subkelas Holocephali. Subkelas Elasmobranchii terbagi menjadi tiga ordo, yaitu Squaliformes, Rajiformes dan Lamniformes. Sedangkan subkelas Holocephali memiliki 2 famili yang umum dikenal, yaitu Chimaeridae dan Rhinochimaeridae (Burhanuddin, A. 2014).

Ikan Pari merupakan salah satu spesies dalam subkelas Elasmobranchii. Ikan pari juga dikenal sebagai Ikan Batoid, yaitu ikan bertulang rawan yang dilengkapi ekor panjang seperti cambuk. Pada pangkal ekor Pari terdapat satu sampai lima duri yang mempunyai jaringan kelenjar racun di sebelah bawahnya. Keberadaan duri tajam itulah yang membuat Pari disebut sebagai Ikan Sting Rays atau Ikan Duri Penyengat. Bagian tersebut digunakan untuk melukai lawannya atau melumpuhkan mangsanya dalam keadaan terancam, bahkan apabila tidak segera ditangani dikhawatirkan dapat menyebabkan kematian. Secara umum Pari mempunyai bentuk tubuh sangat melebar, gepeng, pipih dan sirip dada yang lebar seperti sayap yang bergabung dengan bagian depan kepala. Apabila dilihat dari bawah (posterior) dan bagian atas (anterior), tubuh Pari tampak oval atau membundar. Lebar piringan cakram tersebut dapat mencapai 1,2 kali dari panjangnya. Mata Ikan Pari terletak di bagian samping kepala dan cenderung menonjol. Pada bagian belakang mata terdapat spirakulum yaitu lubang yang berfungsi untuk bernafas. Terdapat celah insang (gill slits) berjumlah lima sampai enam pasang yang terdapat di sisi kepala bagian ventral sebagai tempar pembuangan udara hasil pernafasan. Memiliki mulut tipe terminal, dengan posisi di bagian bawah tubuh. Sirip punggung hampir dikatakan tidak ada atau tidak jelas terlihat (Kinakesti, S. Wahyudewantoro, W., 2017).

Ikan pari mempunyai lingkup sebaran habitat yang cukup luas yaitu di Samudera Atlantik, India dan Pasifik. Ikan Pari mendiami perairan pesisir tropis dan subtropis yang hangat dan beberapa diantaranya dapat dijumpai di perairan tawar. Ikan tersebut seringkali dijumpai berenang bebas di di perairan dengan dasar berlumpur, berpasir, karang sampai berbatu. menginformasikan bahwa beberapa jenis Pari juga dapat ditemukan di perairan pantai sampai tawar, seperti Pari sungai (Himantura signifier) yang hanya dijumpai di perairan tawar dan sesekali masuk ke perairan payau. Pari sering terlihat dalam kelompok kecil maupun sendiri (soliter) dan seringkali terlihat berenang di permukaan air, maupun bagian tengah kolom perairan, bahkan memungkinkan Pari untuk dapat berenang di dasar suatu perairan. 
Letak astronomis PPN Karangantu berada pada koordinat antara $5^{\circ} 50^{\prime}$ LS sampai $6^{\circ} 3^{\prime}$ LS dan $106^{\circ} 9^{\prime}$ BT sampai $106^{\circ} 11^{\prime}$ BT, secara administratif memiliki batasanbatasan sebagai berikut:

1. Sebelah Utara berbatasan dengan Laut Jawa;

2. Sebelah Selatan berbatasan dengan Desa Margaluyu dan Desa Kasunyatan;

3. Sebelah Barat berbatasan dengan Desa Pamengkang; serta

4. Sebelah Timur berbatasan dengan Desa Sawah Luhur.

PPN Karangantu yang mempunyai luas 30 ha, terletak di Desa Banten, Kecamatan Kasemen, Kota Serang, Provinsi Banten. PPN Karangantu memiliki satu Tempat Pelelangan Ikan yang masih berfungsi sebagai sarana aktifitas dan bertemunya nelayan dengan bakul. Hal ini diperkuat oleh Apriani et al. (2013) yang menyatakan bahwa, Pelabuhan Perikanan Nusantara Karangantu merupakan salah satu pusat aktivitas perikanan tangkap di Provinsi Banten dengan produktivitas yang tinggi. Ikan yang didaratkan tidak hanya didistribusikan ke wilayah Provinsi Banten, namun juga dijual ke Jakarta dan Lampung.

\section{METODE}

Penelitian dilaksanakan pada bulan November 2021. Penelitian ini dilakukan di Tempat Pelelangan Ikan (TPI) Karangantu, Serang, Banten, yang letaknya berada di Pelabuhan Karangantu.

Identifikasi ikan pari hasil tangkapan nelayan dilakukan dengan metode survei yang bersifat deskriptif untuk mengetahui gambaran hasil identifikasi keanekaragaman spesies dari ikan pari, serta dilakukan pendekatan pengamatan secara morfologi yaitu dengan melihat dari struktur tubuh luar seperti bentuk tubuh, warna, bentuk ekor serta corak tubuh dari ikan pari. Tahap selanjutnya yaitu dilakukan wawancara dengan para penjual ikan di TPI Karangantu, nelayan, serta WASKI (Pengawas Kapal Ikan) untuk mengetahui jenis-jenis spesies ikan pari. Spesies yang telah didapat lalu didokumentasikan serta di data secara langsung.

Peneliti melakukan observasi pada saat fase bulan terang. Jumlah tangkapan ikan lebih banyak pada bulan gelap dibandingkan dengan bulan terang (Djasmani et al., 2010; Syahputra et al., 2016). Hal ini dikarenakan pada saat fase bulan terang cahaya lampu di kapal tidak efektif menarik ikan berkumpul sekitar kapal karena cahaya bulan lebih terang dari cahaya lampu kapal.

Pengumpulan data merupakan teknik yang digunakan oleh peneliti untuk mendapatkan data yang diperlukan dari narasumber dengan menggunakan banyak waktu. Teknik pengumpulan data pada penelitian ini adalah teknik observasi, dan teknik dokumentasi. Teknik observasi dilakukan dengan cara mengamati dan mencatat secara sistematik terhadap unsur-unsur yang tampak pada objek penelitian, sehingga peneliti akan mengetahui keragaman sampel. Adapun teknik dokumentasi dalam penelitian ini yaitu dengan cara mengumpulkan dokumen-dokumen dari sumber terpercaya untuk mengetahui data dari objek yang akan diteliti tentang keanekaragaman pari.

Data yang dikumpulkan dalam penelitian ini adalah data primer dan data sekunder. Data primer merupakan data yang dikumpulkan secara langsung di lokasi penelitian. Sedangkan data sekunder merupakan data yang diperoleh melalui hasil penelitian sebelumnya, seperti jurnal ilmiah. 


\section{HASIL DAN PEMBAHASAN}

Berdasarkan hasil spesies yang teridentifikasi jumlah pari yang didapatkan sebanyak 27 ekor dari spesies yang berbeda diantaranya yaitu spesies Rhinoptera javanica didapatkan sebanyak 7 ekor, spesies Himantura gerrardi sebanyak 4 ekor, spesies Neotrygon kuhlii sebanyak 5 ekor dan Gymnura poecilura sebanyak 11 ekor.

Tabel 1. Data Hasil Spesies Pari di TPI Karangantu

\begin{tabular}{lllc}
\hline Famili & Spesies & Nama lokal & Status IUCN \\
\hline Rhinopteridae & Rhinoptera javanica & Pari Burung & EN \\
Dasyatidae & Himantura gerrardi & Pari Mondol & VU \\
& Neotrygon kuhlii & Pari Kodok & DD \\
Gymnuridae & Gymnura poecilura & Pari Kupu-kupu & NT \\
\hline
\end{tabular}

Indeks Keanekaragaman jenis Shannon Wiener (Odum 1996) dihitung dengan rumus.

Dimana :

$$
H^{\prime}=\sum_{i=1}^{S}(p i)(\ln p i)
$$

$\mathrm{H}^{\prime}=$ Indeks Diversitas Shannon-Wiener.

$\mathrm{Pi}=$ Indeks kelimpahan

Penentuan kriteria :

$\mathrm{H}^{\prime}<1=$ Keanekaragaman rendah.

$1<\mathrm{H}^{\prime}<3=$ Keanekaragaman sedang.

$\mathrm{H}^{\prime}>3=$ Keanekaragaman tinggi.

Keanekaragaman jenis ikan pari di TPI Karangantu, Serang, Banten termasuk kategori sedang dengan diperolehnya nilai $\mathrm{H}^{\prime}$ sebesar 1,31. Jenis pari yang didapatkan diantaranya adalah pari kupu-kupu, pari mondol, pari burung, dan pari kodok.

Pari Kupu-kupu (Gymnura poecilura). Berdasarkan hasil pengamatan jenis Ikan pari Gymnura Poecilura memiliki bentuk tubuh seperti kupu-kupu dengan bentuk tubuh lebar. Memiliki warna kecoklatan dan terdapat bintik-bintik putih pada bagian punggung. Ikan pari Gymnura Poecilura memiliki ekor lebih pendek dari pada ikan pari lainnya dan memiliki warna ekor belang putih dan hitam. Gymnura Poecilura termasuk kedalam hewan vivipar, dengan ketergantungan embrio pada kuning telurnya, biologinya kurang diketahui namun dilaporkan dapat berkembang biak di air tawar. Makanannya terdiri dari crustacea maupun ikan kecil dan cephalopoda. Sering tertangkap oleh jaring insang dasar. Bagian tubuh yang dapat dimanfaatkan adalah daging dan sirip (keduanya mempunyai nilai ekonomi tinggi), begitu pula kulit serta tulang rawannya. Berdasarkan wawancara yang telah dilakukan dengan nelayan bahwa spesies ini sangat diminati terutama daging dan siripnya yang bernilai ekonomis tinggi, sehingga harga jual untuk spesies ini terbilang lebih mahal dibandingkan dengan ikan pari lainnya (Haryono, 2020).

White et al., (2006) menyatakan bahwa ikan pari spesies ini panjang tubuhnya dapat mencapai $270 \mathrm{~cm}$ dan berukuran $38-40 \mathrm{~cm}$ saat lahir, sebarannya yaitu di seluruh perairan Indo-Pasifik, dari India ke arah timur hingga Melanesia, habitatnya berada di di dasar perairan, juvenil ditemukan di sekitar perairan pantai hutan bakau dan pulau karang, dewasanya ditemukan lebih ke arah lepas pantai pada kedalaman sekitar $100 \mathrm{~m}$. 


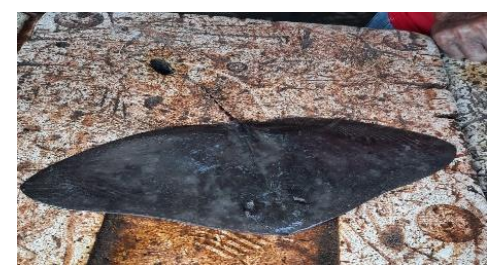

(Sumber: Dokumen pribadi, 2021)

Klasifikasi:

$\begin{array}{ll}\text { Kingdom } & : \text { Animalia } \\ \text { Filum } & : \text { Chordata } \\ \text { Kelas } & : \text { Chondrichthyes } \\ \text { Ordo } & : \text { Myliobatiformes } \\ \text { Famili } & : \text { Gymnuridae } \\ \text { Genus } & : \text { Gymnura } \\ \text { Species } & : \text { Gymnura poecilura }\end{array}$

(Shaw, 1804).

Status konservasi Gymnura poecilura menurut IUCN 2020 yaitu berstatus Near Threatened (Hampir Terancam) adalah status konservasi yang diberikan kepada spesies yang telah dievaluasi tetapi tidak memenuhi syarat untuk masuk dalam kategori terancam punah atau rentan tetapi dapat mengalami konservasi dalam waktu dekat. Spesies ini masih berada dalam jumlah yang cukup banyak di alam. Faktor yang mungkin menyebabkan spesies ini dikategorikan dalam near threatened yaitu spesies ini merupakan hewan yang hidupnya di dalam kawanan dan selalu bersama dalam jumlah yang banyak sehingga perkembangan dan reproduksinya terbilang cepat dan banyak, lalu ketersediaan makanan yang banyak dan melimpah (karena spesies-spesies bukan termasuk spesies yang pemilih terhadap makanannya) (Wijayanti, 2018)

Dalam hal ini, jika terjadi penangkapan secara terus menerus tanpa batas eksploitasi secara berlebih tanpa adanya pengawasan atau pengendalian terhadap kegiatan perikanan dan penangkapan, maka dapat berpotensi menjadi overfishing serta eksploitasi besar-besaran yang dapat menyebabkan menurunnya jumlah populasi spesies-spesies ini di alam bebas dan untuk waktu jangka lama dapat mengalami kepunahan (White et al., 2006).

Ikan pari merupakan salah satu komoditas perikanan yang memberikan kontribusi besar dalam peningkatan perekonomian nelayan di pantai utara Pulau Jawa. Tingginya tangkapan ikan pari dikarenakan hampir seluruh tubuhnya dapat dimanfaatkan dan mempunyai nilai jual tinggi. Selain daging dan siripnya yang digunakan sebagai bahan pangan (dikonsumsi langsung) kulit ikan pari juga diminati sebagai bahan baku industri fashion.

Daging ikan pari selain digunakan sebagai bahan makanan manusia dan ternak, minyaknya dapat digunakan sebagai obat-obatan, tetapi eksploitasinya belum dilakukan secara intensif karena sampai saat ini belum merupakan ikan target utama di dalam usaha perikanan tangkap Indonesia. Ikan pari yang dijual di pasar-pasar ikan biasanya dalam keadaan segar atau sudah dikeringkan, adalah hasil tangkapan sampingan dari jaring trawl dasar, jaring insang dasar, pancing tonda dan pancing dasar dari kapal-kapal perusahaan perikanan dan nelayan-nelayan tradisional (Mansor., et al, 1998 dalam Manik, 2003). 
Pari Mondol (Himantura gerrardi). Himantura gerrardi termasuk dalam kategori Vulnerable (VU) atau Rawan Punah. Spesies ini masuk dalam kategori VU karena menghadapi resiko tinggi konservasi di masa depan. Menurut IUCN (2020) pada Setiati, et al. (2020), Vulnerable (Rentan) adalah kategori yang diberikan kepada spesies yang dianggap menghadapi resiko tinggi konservasi di alam. Kategori VU ini diberikan untuk spesies yang mengalami pengurangan ukuran populasi dalam rentang waktu kurang dari 10 tahun. Hal ini dapat disebabkan karena eksploitasi besar-besaran sehingga jumlah spesies-spesies ikan pari ini di alam mengalami penurunan (Setiati, et al. 2020).

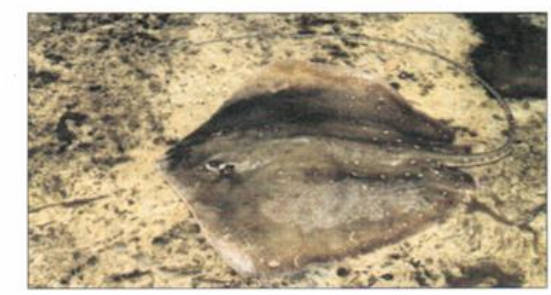

(Pralampita dan Mardlijah, 2017)

Klasifikasi:

$\begin{array}{ll}\text { Kingdom } & \text { : Animalia } \\ \text { Phylum } & \text { : Chordata } \\ \text { Subphylum } & : \text { Vertebrata } \\ \text { Class } & \text { : Elasmobranchii } \\ \text { Order } & : \text { Rajiformes } \\ \text { Famili } & : \text { Dasyatidae } \\ \text { Genus } & : \text { Himantura } \\ \text { Spesies } & \text { : Himantura gerrardi }\end{array}$

(Sudarto, S. 2010)

Menurut Carpenter \& Niem (1999) dalam Pralampita dan Mardlijah (2017), H. gerrardi dalam bahasa inggris disebut whitespotted whipray. Belum ada nama spesifik untuk pari tersebut, tetapi sering dikenal dengan nama pari mondol. $H$. gerrardi mempunyai karakteristik sebagai berikut: cawan berbentuk rhomboid (jajaran genjang), badan tebal, lebar melampaui panjang (kira-kira 1,1 sampai dengan 1,2 kali panjang), puncak sirip dada menyempit, moncong berbentuk segitiga melebar dengan ujung kecil. Ekor berbentuk bulat memanjang (kira-kira 2,5 sampai dengan 3,0 lebar cawan). Bagian ekor seperti cambuk mulai di bawah duri sengat sedikit papih melebar dekat pangkal, kebanyakan memiliki 1 duri sengat. Sirip perut kecil dan hampir berbentuk segitiga. Permukaan atas berwarna abu-abu kecoklatan dengan totol-totol putih yang menyebar di seluruh atau setengah badan bagian belakang. Dasar ekor berwarna kecoklatan dengan totol-totol putih di sepanjang ekor. Pada umumnya pari ini ditangkap untuk diambil kulitnya, setelah itu dikeringkan atau disamak lalu digunakan sebagai bahan baku untuk tas, sepatu, dan dompet, juga dikonsumsi dagingnya (Pralampita dan Mardlijah, 2017).

Pari Burung (Rhinoptera javanica). Pari burung merupakan salah satu jenis ikan pari yang memiliki bentuk badan picak, dan kepala seakan-akan terbagi dua. Kepala menonjol ke depan dengan moncong seperti sapi karenanya ia disebut "cow ray". Gigi berbintik-bintik, keras, tersusun, terdapat 7 baris pada tiap rahang. Lubang penyemburan air besar. Ekornya panjang sekali, menyerupai cambuk, berduri-duri seperti amplas. Termasuk ikan buas, memakan organisme dasar (ikan-ikan dasar, 
moluska, dan crustacea). Ikan ini hidup di dasar perairan. Bagian atas licin dan berwarna merah sawo matang atau warna hitam matang dengan tepian merah keunguan. Ikan ini dapat mencapai panjang $100 \mathrm{~cm}$ lebih. Sebaran dan kelimpahan ikan pari burung mempunyai variasi habitat yang sangat luas dengan pola sebaran yang unik (Cartamil et al., 2003).

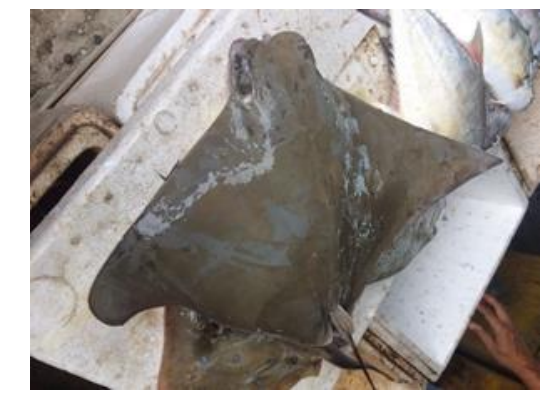

(Sumber: Dokumen pribadi, 2021)

Klasifikasi

$\begin{array}{ll}\text { Kingdom } & \text { : Animalia } \\ \text { Phylum } & \text { : Chordata } \\ \text { Class } & \text { : Chondrichthyes } \\ \text { Ordo } & \text { : Myliobatiformes } \\ \text { Famili } & \text { : Myliobatidae } \\ \text { Genus } & \text { : Rhinoptera } \\ \text { Species } & \text { : Rhinoptera javanica }\end{array}$

(J. P. Müller \& Henle, 1841).

Rhinoptera javanica adalah spesies ikan dalam famili Rhinopteridae. Ini ditemukan di Indo-Pasifik di luar China, India, Indonesia, Iran, Jepang, Madagaskar, Malaysia, Mozambik, Pakistan, Filipina, Seychelles, Somalia, Afrika Selatan, Sri Lanka, Taiwan, Tanzania, dan mungkin Vietnam . Habitat alaminya adalah laut lepas, laut dangkal, dasar perairan subtidal, terumbu karang, perairan muara, dan laguna salin di pesisir. Menurut The IUCN Red List of Threatened Species, pari burung termasuk dalam Endangered Species (Sherman, C.S. et al. 2021)

Daerah sebaran ikan pari burung adalah di sekitar alur dangkal atau muara pertemuan sungai dan laut yang berpasir dan berlumpur kawasan pantai timur, yang kini menjadi sasaran untuk lokasi budidaya hewan tersebut. Ikan pari ini biasa ditemukan di perairan laut tropis (Tam et al., 2003). Di perairan tropis Asia Tenggara (Thailand; Indonesia; Papua Nugini) dan Amerika Selatan (Sungai Amazon). Nelayan umumnya menangkap ikan pari burung ini menggunakan alat tangkap berupa jaring dogol, jaring liong bun, dan pancing senggol. Jaring dogol merupakan alat tangkap yang paling efektif namun kurang bersifat selektif, dimana $>50 \%$ dari total hasil tangkapan berupa ikan-ikan muda. Jaring liong bun dan pancing senggol tergolong selektif, dimana ikan pari muda tertangkap dengan jumlah $<50 \%$ dari total hasil tangkapannya.

Pari Kodok (Neotrygon kuhlii). Tubuh atau lempengan kepala membulat, moncong pendek dengan sudut melebar. Terdapat bintik-bintik hitam yang menyebar melintang melewati mata. Warna tubuhnya coklat kemerahan dengan beberapa bintikbintik biru dan terkadang hitam pada bagian punggung atau dorsal. Panjang ekor hampir sama dengan tubuh, dan mempunyai cincin berwarna hitam dan putih. Umumnya mempunyai satu duri penyengat. Pari ini dapat dijumpai di perairan karang atau 
mendiami dasar perairan yang berpasir dan memangsa udang dan beberapa jenis kepiting. Pari tersebut mempunyai lempengan kepala dengan panjang $40 \mathrm{~cm}$ dan lebar 21,5 cm perairan (Kinakesti, S. Wahyudewantoro, W., 2017).

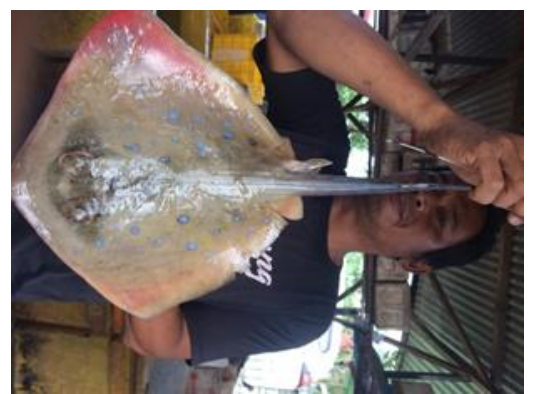

(Sumber: Dokumen pribadi, 2021)

Klasifikasi

$\begin{array}{ll}\text { Kingdom } & \text { : Animalia } \\ \text { Filum } & \text { : Chordata } \\ \text { Kelas } & : \text { Chondrichthyes } \\ \text { Ordo } & : \text { Myliobatiformes } \\ \text { Famili } & : \text { Dasyatidae } \\ \text { Genus } & : \text { Neotrygoninae } \\ \text { Spesies } & : \text { Neotrygon kuhlii }\end{array}$

(Lubis, dkk., 2021)

Sebaran dan habitat dari ikan pari spesies ini terbilang luas. mengatakan bahwa famili Dasyatidae mempunyai variasi habitat yang sangat luas dengan pola sebaran yang unik. Daerah sebaran ikan pari adalah perairan pantai dan kadang masuk ke daerah pasang surut. Ikan pari biasa ditemukan di perairan laut tropis. Di perairan tropis Asia Tenggara (Thailand, Indonesia, Papua Nugini) dan Amerika Selatan (Sungai Amazon), sejumlah spesies ikan pari bermigrasi dari perairan laut ke perairan tawar. Neotrygon kuhlii merupakan ikan demersal di perairan dangkal dan paparan benua pada kedalaman hingga $90 \mathrm{~m}$. Vivipar dengan kecenderungan histotrofi melahirkan 1-2 ekor anak dengan masa kandungan yang belum diketahui, waktu musim kawin tidak tetap dan makanannya terdiri dari crustacea dan ikan-ikan kecil. Umum dijumpai di perairan Indo-Pasifik Barat sampai Melanesia, termasuk selatan Jepang dan Australia, kemungkinan pula mencapai bagian tenggara Afrika, biasanya tertangkap dalam jumlah yang banyak oleh pukat dasar, jaring udang dan perangkap ikan (Wijayanti, dkk. 2018). Manfaat Ikan Pari Kodok atau Neotrygon kuhlii menurut Wijayanti, dkk (2018).

1. Bagian tubuh yang dimanfaatkan adalah dagingnya, tapi kurang bernilai ekonomi karena ukuran tubuhnya yang kecil.

2. Berdasarkan wawancara dengan nelayan dan masyarakat sekitar bahwa Neotrygon kuhlii ini biasa diolah menjadi ikan asin yang akan dikonsumsi untuk pribadi maupun dikirim ke luar daerah sesuai permintaan.

Neotrygon kuhlii merupakan salah satu spesies ikan pari yang masuk kedalam kategori kekurangan data atau data deficient (DD). Hal yang menyebabkan kedua spesies ikan pari ini mengalami kekurangan data bisa disebabkan biologi dan perilaku yang belum banyak diketahui, sebaran dan habitat yang luas dan tidak menentu sehingga menyebabkan sulitnya para peneliti melakukan penelitian dan pendataan, juga 
sifat dari kedua spesies ini yang bisa dikatakan sebagai hewan kosmopolit (spesies yang keberadaanya dapat ditemukan hampir di seluruh habitat dan ekosistem, dalam hal ini "perairan") dan nilai ekonomis yang rendah sehingga potensi penangkapan dan eksploitasi kurang diminati (Wijayanti, dkk. 2018).

Fase Bulan Terang. Peneliti melakukan observasi pada bulan November 2021 bertepatan dengan fase bulan terang. Jumlah tangkapan ikan lebih banyak pada bulan gelap dibandingkan dengan bulan terang (Djasmani et al., 2010; Syahputra et al., 2016).

Pada saat fase bulan terang cahaya lampu di kapal tidak efektif menarik ikan berkumpul sekitar kapal karena cahaya bulan lebih terang dari cahaya lampu kapal. Hal ini menyulitkan para nelayan dalam mengumpulkan ikan pada fase bulan terang sehingga banyak nelayan memilih tidak melaut pada fase bulan terang. (Lumban-Gaol, et al. 2019). Rata-rata jumlah kapal yang beroperasi pada fase bulan terang maupun pada fase bulan gelap berfluktuasi. Jumlah kapal cenderung tinggi pada musim peralihan dan musim timur serta cenderung rendah di musim barat. Kondisi ini juga sama dengan hasil penelitian sebelumnya dimana jumlah nelayan yang melaut pada musim barat lebih sedikit dibandingkan musim timur (Karubaba et al., 2001). Rendahnya jumlah kapal-kapal ikan yang beroperasi pada musim barat disebabkan beberapa faktor seperti kondisi cuaca yang tidak baik. Hasil kajian menunjukkan bahwa tinggi gelombang signifikan di Laut Jawa lebih besar pada musim barat antara 0,44 $1.183 \mathrm{~m}$ dibandingkan dengan musim timur antara 0,35-1,06 m (Hadi et al., 2005). Selain itu, pada saat musim barat populasi ikan di Laut Jawa lebih sedikit (Hendiarti, 2016).

\section{SIMPULAN}

Berdasarkan hasil penelitian ini dapat disimpulkan bahwa keragaman spesies ikan pari di TPI Karangantu yaitu sebanyak 27 ekor. Spesies pari yang ditemukan yaitu Pari Kupu-kupu, Pari Mondol, Pari Burung dan Pari Kodok. Spesies pari yang ditemukan memiliki status konservasi yang berbeda-beda, yaitu Pari Kupu-kupu memiliki status konservasi Near Threatened (Hampir Terancam), Pari Mondol memiliki status konservasi Vulnerable (Rawan Punah), Pari Burung memiliki status konservasi Endangered Species (Langka) dan Pari Kodok memiliki status konservasi Data Deficient (Kekurangan Data). Dari hasil perhitungan indeks keanekaragaman spesies dengan rumus Shannon Wiener termsuk kedalam kategori sedang.

\section{DAFTAR RUJUKAN}

Burhanuddin, A. I. (2014). Ikhtiologi, Ikan dan Segala Aspek Kehidupannya. Yogyakarta: Deepublish.

Cartamil, et al. (2003). Diel movement patterns of the Hawaiian stingray, Dasyatis lata: implications for ecological interactions between sympatric elasmobranch species. Marine Biology. Vol. 142: 841-847

Djasmani, S. S., Djumanto, D., \& Sari, S. T. (2010). Komposisi udang hasil tangkapan jaring ciker pada nelayan Tegalkamulyan di Kabupaten Cilacap. Jurnal Perikanan Universitas Gadjah Mada. Vol. 12(2), 64-71.

Hadi, S., Ningsih, N. S., \& Pujiana, K. (2005). Studi awal pemodelan medan gelombang di Laut Jawa dan karakteristik spektrum energi gelombang di Teluk Jakarta. Ilmu Kelautan: Indonesian Journal of Marine Sciences. Vol. 10(3), 169-176. 
Haryono, Gandri M., Firdaus, Sumarlin, Syamsidar Gaffar, dan Mazlan. (2020). Keanekaragaman Spesies Dan Status Konservasi Ikan Pari (Elasmobranchii) Di Perairan Tarakan. Jurnal Harpodon Borneo. Vol. 13 (1): 39-47

Hendiarti, N. (2016). Hubungan Antara Keberadaan Ikan Pelagis Dengan Fenomena Oseanografi Dan Perubahan Iklim Musiman Berdasarkan Analisis Data Penginderaan Jauh. Majalah Ilmiah Globë. Vol. 10(1), 19-25

Karubaba, C. T., Dietrich, G. B., \& Nikijuluw, V. P. (2001). Kajian Pemenuhan Kebutuhan Pangan Nelayan pada Musim Timur dan Musim Barat Kaitannya dengan Pemanfaatan Sumberdaya Pesisir - study of needs assessment of fishermen food on two monsoon seasons in relation with coastal resource uses. Indones $J$ Coast Mar Resour. Vol. 3(3), 1-11.

Kinakesti, S. Wahyudewantoro, W. (2017). Kajian Jenis Ikan Pari (Dasyatidae) Di Indonesia. Jurnal Fauna Indonesia. Vol. 16 (2): 17-25

Lubis, dkk. (2021). Inventarisasi Ikan Demersal dan Ikan Pelagis yang Didaratkan di PPI Kijang Kecamatan Bintan Timur Kabupaten Bintan. Jurnal Akuatiklestari. Vol. 4 No. 2: $47-57$

Lumban-Gaol, et al. (2019). Distribusi Kapal Ikan Pada Fase Bulan Gelap dan Terang Berdasarkan Data Sensor Visible Infrared Imaging Radiometer Suite (Viirs) di Laut Jawa. Jurnal Kelautan Nasional. Vol. 14(3). 135-144.

Manik, Nurdin. (2003). Beberapa Catatan Mengenai Ikan Pari. Oseana. Vol. 28 (4): 1723

Pralampita, W. A., \& Mardlijah, S. (2017). Aspek biologi pari mondol (Himantura gerrardi) Famili Dasyatidae dari perairan Laut Jawa. Jurnal Penelitian Perikanan Indonesia. 12(1): 69-75

Setiati, N., Lestari, N. A., Partaya, P., \& Priyono, B. (2020). Kajian Aspek Biologi dan Status Kepunahan Ikan Pari yang Diperdagangkan di TPI Pantai Utara Jawa Tengah. Prosiding SNPBS (Seminar Nasional Pendidikan Biologi dan Saintek) Ke-5.

Sherman, C.S. et al. (2021). Rhinoptera javanica. The IUCN Red List of Threatened Species.

Sudarto, S. (2010). Ikan Pari Air Tawar dan Sejenisnya sebagai Ikan Hias yang Potensial. Jurnal Media Akuakultur. 5(1): 15-17

White, W. T., P. R. Last., J. D. Stevens., G. K. Yearsley. F \& Dharmadi. (2006). Economically Important Shark and Rays of Indonesia. Australia: Australian Center for International Agricultural Research.

Wijayanti, et al. (2018). Keanekaragaman Spesies dan Status Konservasi Ikan Pari Di Tempat Pelelangan Ikan Muara Angke Jakarta Utara. Jurnal Biodjati. Vol.3 (1). 